\title{
Mepolizumab in a population with severe eosinophilic asthma and corticosteroid dependence: results from a French early access programme
}

\author{
Camille Taillé $1,2,3$, Pascal Chanez ${ }^{3,4,5}$, Gilles Devouassoux ${ }^{3,6,7}$, Alain Didier ${ }^{3,8}$, \\ Christophe Pison ${ }^{3,9,10}$, Gilles Garcia ${ }^{3,11,12}$, Jeremy Charriot (1) ${ }^{13}$, \\ Stéphane Bouée ${ }^{14}$, Alina Gruber ${ }^{15}$, Celine Pribil (15 ${ }^{15}$, Arnaud Bourdin ${ }^{3,13}$ and \\ Marc Humbert (10),11,12
}

@ERSpublications

Mepolizumab is associated with improvements in several clinically meaningful outcomes and demonstrates a favourable safety profile in a population with severe eosinophilic asthma, outside of the controlled environment of a clinical trial https://bit.ly/3bckeQ3

Cite this article as: Taillé C, Chanez P, Devouassoux G, et al. Mepolizumab in a population with severe eosinophilic asthma and corticosteroid dependence: results from a French early access programme. Eur Respir J 2020; 55: 1902345 [https://doi.org/10.1183/13993003.02345-2019].

\section{ABSTRACT}

Background: Mepolizumab was available in France as part of an early access programme for patients with severe eosinophilic asthma (nominative autorisation temporaire d'utilisation [temporary use authorisation] (nATU)) before its commercialisation. This study aimed to characterise patients who received mepolizumab in the nATU.

Methods: This retrospective, observational study analysed data from the hospital medical records of patients up to 24 months after treatment initiation. Study objectives were to describe patient baseline characteristics, the evolution of disease severity and treatment modifications during follow-up; safety was also investigated.

Findings: Overall, 146 patients who received $\geqslant 1$ dose of mepolizumab were included. At inclusion, patients had a mean age of 58.2 years with a mean severe asthma duration of 13.4 years, and $37.0 \%$ had respiratory allergies. Patients experienced, on average, 5.8 exacerbations per patient per year at baseline, 0.6 and 0.5 of which required hospitalisation and emergency department visits, respectively. These values improved to $0.6,0.1$ and 0.1 exacerbations per patient per year, respectively, at 24 months of follow-up. Most patients (92.8\%) were using oral corticosteroids at baseline, compared with $34.7 \%$ by 24 months of follow-up. Moreover, mean blood eosinophil counts improved from 722 cells $\mu \mathrm{L}^{-1}$ at baseline to 92 cells $\mu \mathrm{L}^{-1}$ at 24 months of follow-up; lung function and asthma control followed a similar trend.

Interpretation: Results confirm findings from clinical trials, demonstrating that mepolizumab is associated with important improvements in several clinically meaningful outcomes and has a favourable safety profile in a population with severe eosinophilic asthma, outside of the controlled environment of a clinical trial.

This article has supplementary material available from erj.ersjournals.com

Received: 6 Dec 2019 | Accepted after revision: 14 March 2020

Copyright CERS 2020. This version is distributed under the terms of the Creative Commons Attribution NonCommercial Licence 4.0. 


\section{Introduction}

Asthma is a common respiratory disease affecting approximately 360 million people worldwide and an estimated 3.5-10.3\% of the population in France [1,2]. A small proportion of patients with asthma suffer from severe asthma [3], which consists of several clinically distinct phenotypes and endotypes [4-7]. The severe eosinophilic phenotype is characterised by persistent eosinophilic inflammation, reduced lung function and asthma control, and recurrent exacerbations despite the use of high-dose inhaled corticosteroids (ICS), other controllers and chronic or repeated use of systemic corticosteroids [4, 8].

Mepolizumab, an anti-interleukin-5 monoclonal antibody, selectively inhibits eosinophilic inflammation [9] and is approved as an add-on treatment for patients with severe eosinophilic asthma [10-12]. Randomised controlled trials (RCTs) have shown that, compared with placebo, mepolizumab reduces the rate of exacerbations, decreases oral corticosteroid (OCS) dependence, and improves lung function, asthma control and health-related quality of life [13-16]. Although data from RCTs can confer critical insights into the clinical efficacy and safety of a therapy, these studies are often designed to meet one specific primary objective, such as assessing changes in OCS dose or exacerbation rate. Moreover, RCTs can include a limited patient population, which is not reflective of the general asthma population, due to narrow eligibility criteria [17]. It is therefore also important to obtain data on the effects of a treatment outside the constraints of a formal clinical trial.

Mepolizumab was approved for use in patients with severe eosinophilic asthma in the European Union in December 2015 [10]. Patients in France were given access to mepolizumab before it became commercially available in February 2018, as part of an early access programme (nominative autorisation temporaire d'utilisation [temporary use authorisation] (nATU)), and were later reimbursed by Sécurité Sociale [18]. The nATU was restricted to patients deemed unable to wait for commercialisation due to disease severity. A protocol was established between the Agence Nationale de Sécurité du Médicament et des Produits de Santé (ANSM) and the manufacturer (GlaxoSmithKline), which mandated the patient monitoring procedure, collection of data relating to efficacy and safety and actual conditions of use. To understand the typical patient pathway and describe the characteristics of patients who received early mepolizumab treatment in a real-world setting, data collected during the nATU plus data retrospectively collected from patient medical records were analysed. The aim was to characterise patients included in the nATU and describe disease severity evolution and treatment modifications up to 24 months after treatment initiation.

\section{Methods}

\section{Study design and treatment}

This retrospective, observational study (GSK ID: 207943; HO-17-18317) included data from hospital medical records of patients with severe eosinophilic asthma who started mepolizumab treatment (100 mg subcutaneously 4-weekly) in France as part of the nATU. Medical data mandated by the nATU protocol were collected from June 9, 2015, to March 2, 2016 (during the nATU), and from March 2, 2016, to February, 2018 (post-nATU), which allowed for a retrospective follow-up period of up to 24 months following treatment initiation. Data recorded during and after the nATU but not mandated by the nATU protocol were also included. This study was declared to the Expert Committee for Research, Studies and Evaluations in Health on December 21, 2017, and the declaration of compliance with reference methodology MR003 was made to the National Commission for Data Protection and Liberties on January 8, 2018.

\section{Participating medical centres}

Participating medical centres had $\geqslant 3$ patients in the nATU and agreed to their participation. The majority of pulmonology departments involved in this study were based at university hospitals (further details in supplementary section 1 ).

Affiliations: ${ }^{1}$ Service de Pneumologie, Hôpital Bichat, AP-HP-Nord, Paris, France. ${ }^{2}$ INSERM U1152, Université de Paris, Paris, France. ${ }^{3}$ INSERM 12, F-CRIN, Clinical Research Initiative In Severe Asthma: a Lever for Innovation \& Science (CRISALIS), France. ${ }^{4}$ Clinique des bronches allergies et sommeil, CIC nord, C2VN Marseille, Marseille, France. ${ }^{5}$ INSERM U1062, Dept of Respiratory Diseases, Aix-Marseille University, Marseille, France. ${ }^{6}$ Service de Pneumologie, Hôpital de la Croix Rousse, Hospices Civils de Lyon, Lyon, France. ${ }^{7}$ Université Claude Bernard Lyon 1, Villeurbanne, France. ${ }^{8}$ Service de Pneumologie, Hôpital Larrey CHU de Toulouse, Toulouse, France. ${ }^{9}$ Service Hospitalier Universitaire Pneumologie Physiologie, Pôle Thorax et Vaisseaux, Université Grenoble Alpes, CHU Grenoble Alpes, Grenoble, France. ${ }^{10}$ INSERM U1055, Université Grenoble Alpes, La Tronche, France. ${ }^{11}$ Université Paris-Sud, and Université Paris-Saclay, Hôpital Bicêtre, Le Kremlin-Bicêtre, Paris, France. ${ }^{12}$ Service de Pneumologie et Soins Intensifs Respiratoires and INSERM U999, Hôpital Bicêtre, AP-HP, Le Kremlin-Bicêtre, Paris, France. ${ }^{13}$ Service de Pneumologie and INSERM CNRS, CHU Montpellier, Université de Montpellier, Montpellier, France. ${ }^{14}$ Real World Evidence, CEMKA, Bourg La Reine, France. ${ }^{15}$ Laboratoire GSK France, Rueil Malmaison, France.

Correspondence: Marc Humbert, Service de Pneumologie et Soins Intensifs Respiratoires, Hôpital Bicêtre, 78 rue du Général Leclerc, 94270 Le Kremlin-Bicêtre, Paris, France. E-mail: marc.humbertdaphp.fr 


\section{Patients}

Patients enrolled in the nATU received $\geqslant 1$ injection of mepolizumab at a participating centre, evidenced by physician-completed treatment access forms. All delays of $4 \pm 1$ weeks between two consecutive mepolizumab injections were to be reported. To justify the request for mepolizumab and help inform subsequent validation by the ANSM and GlaxoSmithKline, physicians were required to certify that: the patient had severe eosinophilic asthma (without features of eosinophilic granulomatosis with polyangiitis); no other suitable treatment options were currently available; inclusion in a RCT wasn't possible; and the patient's clinical health status required an urgent change of treatment to avoid severe exacerbations and/or severe steroid side effects. Treatment access forms included information on blood eosinophil counts, exacerbation rates, symptom control and OCS dose. No strict eligibility criteria were described to allow the request validation by GlaxoSmithKline, and patients had to be willing to disclose their personal medical records.

\section{Endpoints and assessments}

The primary objective was to describe the profile of patients included in the nATU, using additional data to those collected within the nATU. Baseline characteristics were assessed over the 12 months preceding mepolizumab initiation, and included: asthma duration; smoking history; geographic localisation; comorbidities; employment status; asthma-induced disability; socio-economic status; complementary health insurance status; number of asthma-related exacerbations, including those requiring hospitalisation or an emergency department (ED) visit; atopic status; blood immunoglobulin (Ig)E, eosinophil and neutrophil levels; OCS dose; previous treatment adherence (estimated by investigators); forced expiratory volume in $1 \mathrm{~s}\left(\mathrm{FEV}_{1}\right)$; and $\mathrm{FEV}_{1} /$ forced vital capacity (FVC) ratio. Asthma exacerbations were defined as disease worsening requiring an emergency department visit, hospitalisation and/or use of OCS for $\geqslant 48 \mathrm{~h}$ or an increase of $\geqslant 50 \%$ in daily OCS dose. Atopic status was determined by $\geqslant 1$ positive skin prick test or allergen-specific IgE blood test (IgE level $>0.1 \mathrm{UI}$ ).

Secondary objectives were to describe the evolution of disease control and treatment modifications during the follow-up period ( $\leqslant 24$ months after mepolizumab initiation). To assess these, we examined: the number of exacerbations and how they were managed (e.g. whether OCS, an mergency department visit and/or hospitalisation were required); $\mathrm{FEV}_{1} ; \mathrm{FEV}_{1} / \mathrm{FVC}$ ratio; and mepolizumab withdrawal date and reason (if applicable). Asthma exacerbation rates and OCS use/dose were also analysed by blood eosinophil count at inclusion $\left(<300,300-<500,500-<700\right.$ and $\geqslant 700$ cells. $\left.\mu \mathrm{L}^{-1}\right)$ and an analysis to evaluate the different levels of patients' responses to mepolizumab over the first 12 months of treatment (based on a $\geqslant 50 \%$ reduction in exacerbation rate and $\mathrm{a} \geqslant 50 \%$ reduction in OCS dose) was also performed (supplementary sections 2 and 3). Safety endpoints included incidence of adverse events, serious adverse events (SAEs) and adverse events of interest.

\section{Statistical analyses}

Mean asthma exacerbation rates were reported as exacerbations per patient per year; the evolution of exacerbation rates was analysed using a Poisson regression model. A trend analysis was performed on the $\mathrm{FEV}_{1}, \mathrm{FVC}, \mathrm{FEV}_{1} / \mathrm{FVC}$ ratio data, Asthma Control Test (ACT) scores and blood eosinophil counts across the inclusion and follow-up periods using a mixed linear model with repeated measurements. A KaplanMeier method was used to estimate the duration of treatment with mepolizumab. Statistical analysis was conducted using SAS software (version 9.4 SAS institute Inc., Cary, NC, USA).

\section{Results}

\section{Patient population}

Of the 160 patients included in the nATU, 146 (91.9\%) from 20 participating centres receiving $\geqslant 1$ injection of mepolizumab were included in this study; $13(8.1 \%)$ patients did not receive mepolizumab and were excluded (supplementary figure S1). One patient received mepolizumab to treat severe chronic obstructive pulmonary disease, while awaiting a lung transplantation, and was considered ineligible by the Scientific Committee and excluded from all analyses except the safety analyses. Overall, 61 patients (41.8\%) had 103 injections with a delay $>4$ weeks. The reasons for these delays were only documented for 19 injections and included departure for holidays, death of a relative, health problem unrelated to mepolizumab and that the patient forgot.

Baseline demographics and clinical characteristics are outlined in table 1. Of the 62 patients with confirmed allergies, 54 (87.1\%) were sensitised to aeroallergens (pollen, dander, mould, cockroaches), 12 (19.4\%) had food allergies and five $(8.1 \%)$ had skin allergies. Almost all patients $(93.8 \%)$ had $\geqslant 1$ comorbidity; the most common were ear, nose and throat pathologies $(56.2 \%)$, cardiovascular diseases (35.0\%) and gastro-oesophageal reflux disease (38.7\%) (table 1). In addition, $38.7 \%$ of patients had nasal polyps, $17.5 \%$ had allergic rhinitis and $16.1 \%$ had aspirin-exacerbated respiratory disease. 
TABLE 1 Baseline demographics and clinical characteristics

Total $N=146$

\begin{tabular}{|c|c|}
\hline Age years & $58.2 \pm 13.6$ \\
\hline \multicolumn{2}{|l|}{ Sex } \\
\hline Female & $66(45.2)$ \\
\hline BMI $\mathrm{kg} \cdot \mathrm{m}^{-2}(\mathrm{~N}=137)$ & $27.2 \pm 5.1$ \\
\hline Patients with $\mathrm{BMI} \geqslant 30$ & 32 (21.9) \\
\hline Duration of severe asthma years $(\mathrm{N}=128)$ & $13.4 \pm 12.1$ \\
\hline Respiratory allergies & $54(37.0)$ \\
\hline Disability due to asthma ${ }^{\#}(\mathrm{~N}=127)$ & $29(22.8)$ \\
\hline \multicolumn{2}{|l|}{ Smoking ( $N=145$ ) } \\
\hline Current & $11(7.6)$ \\
\hline Never smoked & $77(53.1)$ \\
\hline Blood eosinophil count cells. $\mu \mathrm{L}^{-1}(\mathrm{~N}=130)$ & $721.7 \pm 500.0$ \\
\hline Blood lgE total level kIU.L ${ }^{-1}(\mathrm{~N}=78)$ & $563.4 \pm 773.0$ \\
\hline Blood neutrophil count $\times 10^{9}$ cells $\cdot \mathrm{L}^{-1}(\mathrm{~N}=120)$ & $6.4 \pm 3.5$ \\
\hline ACT score $(\mathrm{N}=62)$ & $10.2 \pm 4.5$ \\
\hline $\mathrm{FEV}_{1} \mathrm{~mL}(\mathrm{~N}=142)$ & $1883.0 \pm 823.2$ \\
\hline $\mathrm{FEV}_{1} \%$ predicted value $(\mathrm{N}=142)$ & $62.0 \pm 19.4$ \\
\hline $\mathrm{FEV}_{1} / \mathrm{FVC}$ ratio $(\mathrm{N}=58)$ & $58.8 \pm 12.5$ \\
\hline \multicolumn{2}{|l|}{ Comorbidities } \\
\hline Any comorbidity & 137 (93.8) \\
\hline AERD & $22(16.1)$ \\
\hline Allergic rhinitis & $24(17.5)$ \\
\hline Cardiovascular disease & $48(35.0)$ \\
\hline Depression/anxiety & $29(21.2)$ \\
\hline Diabetes & $26(19.0)$ \\
\hline Dyslipidaemia & $17(12.4)$ \\
\hline GORD & 53 (38.7) \\
\hline Nasal polyps & 53 (38.7) \\
\hline Osteoporosis & $51(37.2)$ \\
\hline Other comorbidities & $46(33.6)$ \\
\hline Sleep apnoea syndrome & $31(22.6)$ \\
\hline Smoking/smoking-related comorbidities & $8(5.8)$ \\
\hline Prior omalizumab treatment & 91 (65.9) \\
\hline \multicolumn{2}{|l|}{ Current treatment } \\
\hline OCS & 128 (92.8) \\
\hline Methylprednisolone & $2(1.6)$ \\
\hline Prednisolone & $11(8.9)$ \\
\hline Prednisone & $111(89.5)$ \\
\hline Other anti-asthmatic treatment & 136 (93.2) \\
\hline \multicolumn{2}{|c|}{$\begin{array}{l}\text { Data are presented as mean } \pm \text { SD or } n(\%) \text {. Data were available for all patients unless otherwise stated. } \\
\text { Blood eosinophil count was the highest value in the previous } 12 \text { months. BMI: body mass index; IgE: } \\
\text { immunoglobulin } E_{;} \text {ACT: Asthma Control Test; } \mathrm{FEV}_{1} \text { : forced expiratory volume in } 1 \mathrm{~s} \text {; FVC: forced vital } \\
\text { capacity; AERD: aspirin-exacerbated respiratory disease; GORD: gastro-oesophageal reflux disease; OCS: } \\
\text { oral corticosteroid. "\#: Declarative item. }\end{array}$} \\
\hline
\end{tabular}

Furthermore, most patients (92.8\%) were receiving OCS at inclusion (mean daily dose $20.6 \pm 16.5 \mathrm{mg}$ prednisolone equivalent), and $65.9 \%$ had previously received omalizumab (table 1).

In the 12 months preceding mepolizumab initiation, the mean rate of exacerbations was 5.8 events per patient per year, 0.6 and 0.5 of which required hospitalisation and emergency department visits, respectively (table 2). The mean blood eosinophil count at baseline was 722 cells $\mu \mathrm{L}^{-1}$ and a large proportion $(n=115,86.5 \%)$ of patients reported their asthma as having a significant impact on their daily activities.

\section{Follow-up data}

Patients attended on average 8.4 follow-up visits after treatment initiation; the mean follow-up duration was 24.2 months owing to some patients infrequently returning to hospital and having a final visit date that exceeded 24 months. Consecutive injections of mepolizumab were administered, on average, 4.2 weeks apart. A total of 48 patients discontinued mepolizumab during follow-up with the majority reporting a 


\begin{tabular}{lccc} 
TABLE 2 Summary of exacerbations during the baseline and follow-up periods & \\
& $\begin{array}{c}\text { Baseline } \\
\text { (N=134) }\end{array}$ & $\begin{array}{c}\mathbf{1 2} \text { months } \\
\text { (N=96) }\end{array}$ & $\begin{array}{c}\text { 24 months } \\
\text { (N=75) }\end{array}$ \\
\hline $\begin{array}{l}\text { Patients with no exacerbations } \\
\text { Exacerbations events per patient per year }\end{array}$ & $5.8 \pm 4.4$ & $\begin{array}{c}48(50.0) \\
0.8 \pm 1.1\end{array}$ & $34(45.3)$ \\
$\begin{array}{l}\text { Exacerbations requiring hospitalisation events per } \\
\text { patient per year }\end{array}$ & $0.6 \pm 1.5$ & $0.1 \pm 0.4$ & $0.1 \pm 0.4$ \\
$\begin{array}{l}\text { Exacerbations requiring an emergency department } \\
\text { visit events per patient per year }\end{array}$ & $0.5 \pm 0.9$ & $0.1 \pm 0.3$ & $0.1 \pm 0.3$
\end{tabular}

Data are presented as $\mathrm{n}(\%)$ or mean \pm SD. At baseline, 12 patients had missing data. At months 12 and 24 of follow-up, 42 and 31 patients had discontinued treatment, and eight and 40 had no follow-up, respectively.

lack of efficacy or lack of efficacy associated with an adverse event ( $n=29)$ (supplementary table S1). 3 months after their first injection, $91 \%$ of patients were still receiving mepolizumab; this reduced to $81 \%$ by 6 months and subsequently to $69 \%$ and $66 \%$ at months 12 and 24 .

Mean exacerbation rates for total exacerbations and for those requiring hospitalisation and emergency department visits were lower on-treatment than at baseline (table 2); this trend was observed regardless of blood eosinophil counts at inclusion (supplementary table S2). Compared with baseline, fewer patients used maintenance OCS during follow-up ( $92.8 \%$ at baseline versus $41.1 \%$ and $34.7 \%$ at 12 and 24 months) and those still using OCS required lower doses (figure 1); similar trends were seen when data were stratified by blood eosinophil counts at inclusion (supplementary figure S3 and supplementary table S3). Mean \% predicted pre-bronchodilator $\mathrm{FEV}_{1}$ improved versus baseline at all follow-up time points; mean $\mathrm{FEV}_{1}$ steadily increased to approximately $70 \%$ of the predicted value during the first 10 months of treatment and then stabilised (figure 2a). Mean $\mathrm{FEV}_{1} / \mathrm{FVC}$ ratios also increased during the first 10 months of treatment and then stabilised. After 3 months of mepolizumab the mean ACT score was 17.4 points; this surpassed the minimal clinically important difference (MCID) of $\geqslant 3$ points from baseline (10.2 points) and the response was sustained throughout the study period (figure $2 b$ and $c$ ). Mean \pm SD baseline blood eosinophil counts (cells $\mu \mathrm{L}^{-1}$ ) decreased from $722 \pm 500.0$ to $101 \pm 83.9$ at 3 months, $75 \pm 63.7$ at 12 months, and $92 \pm 72.3$ at 24 months (figure 3).

\section{Safety}

During the study, 276 pharmacovigilance events were reported by 100 patients. Of these, 103 corresponded to drug misuse (all reporting an incorrect dosing interval); 173 were identified as adverse events possibly related to mepolizumab according to patients' medical records. A total of 99 patients reported 159 non-serious adverse events; 41 patients discontinued mepolizumab as a result of these events (29 reported "drug considered ineffective"). The most commonly reported adverse events which were possibly drug-related ( $n \geqslant 5 \%$ of events) included: drug considered ineffective $(n=31)$; headache $(n=14)$; asthenia $(\mathrm{n}=12)$; and asthma $(\mathrm{n}=10)$ (table 3$)$. Adverse events of interest included five events in the system organ class (SOC) category "infections and infestations", five events in "vascular disorders", two events related to "allergic and non-allergic reactions" and one event in "local injection site reactions" (table 4). A total of eight patients reported 14 SAEs that were possibly drug related; the most common was asthma $(\mathrm{n}=3$ events). In this study, no patients experienced severe systemic reactions, severe cardiac adverse events or neoplasms. One death was reported (resulting from an asthma exacerbation) and deemed unrelated to mepolizumab by the physician.

\section{Discussion}

Early access programmes (e.g. the nATU) allow patients who do not meet the strict eligibility criteria for RCTs, but might still benefit from mepolizumab treatment, to gain access to the drug before its commercialisation. Moreover, data collected from these programmes can provide insights on the wider use of mepolizumab in a patient population that closely resembles real life [19]. Here, we investigated the effectiveness and safety of mepolizumab using data from patients with severe eosinophilic asthma enrolled in the nATU. We found that mepolizumab was associated with several clinical benefits, including clinically meaningful reductions in exacerbations and daily OCS doses, consistent with results from two RCTs that assessed these outcomes separately [14].

We identified several indicators of severe disease among patients in the nATU, which included high annual exacerbation rates, with most patients requiring maintenance OCS and experiencing a considerable 
Mean OCS dose\# at inclusion: $20.6 \pm 16.5$
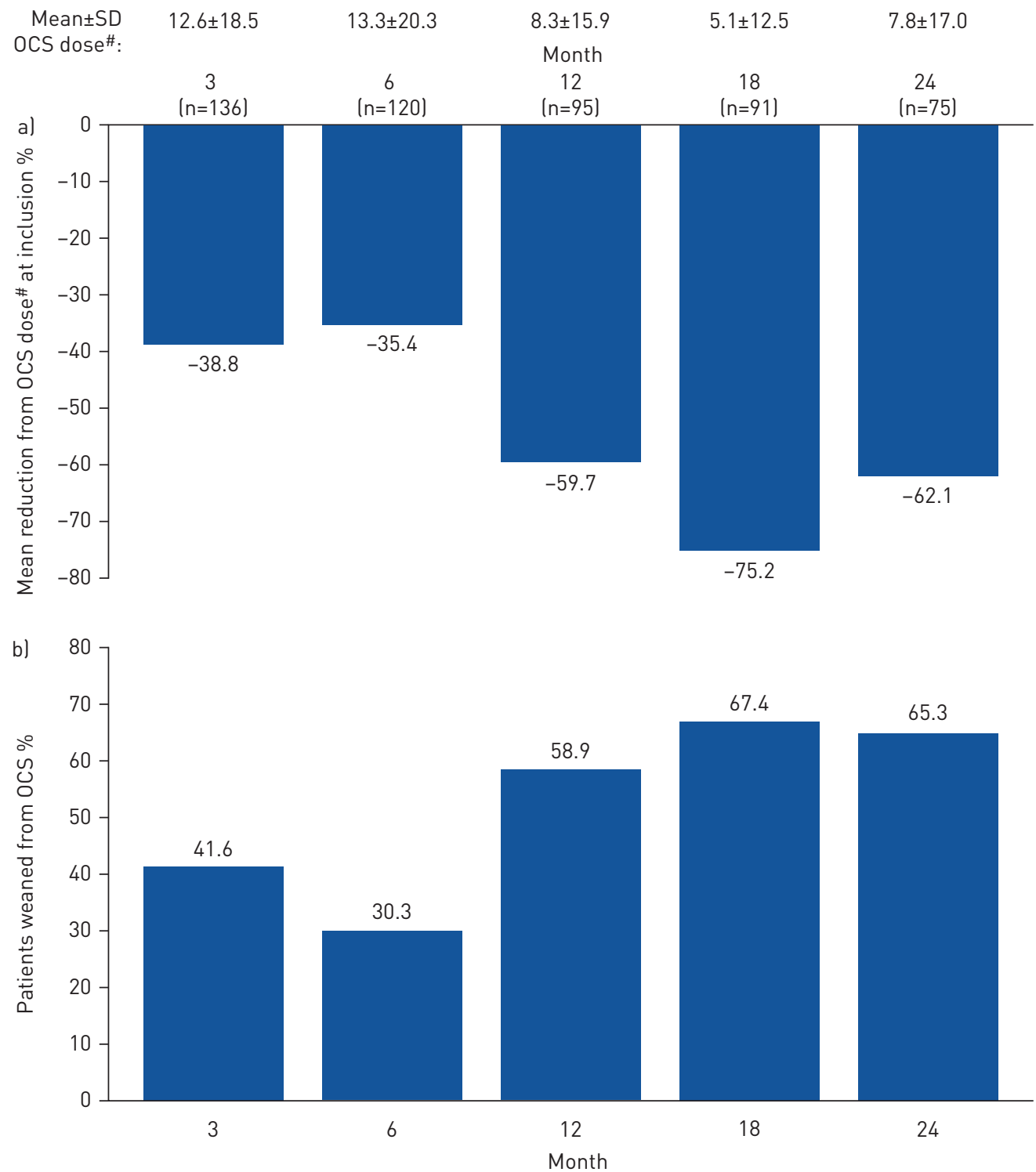

FIGURE 1 a) Change in mean oral corticosteroid (OCS) dose and b) proportion of patients not receiving maintenance OCS during follow-up period. ${ }^{\#}$ : mg prednisolone equivalent. At baseline, eight patients had missing data. At months 12 and 24 of follow-up, 42 and 31 patients had discontinued treatment, and eight and 40 had no follow-up, respectively.

disease burden. The degree of disease severity among these patients was generally greater than that of those enrolled in RCTs. For instance, patients enrolled in the Phase III MENSA and MUSCA studies had a mean rate of 2.7-3.8 exacerbations per year before screening (versus 5.8 in this study) $[13,15]$. Additionally, the proportion of patients in this study requiring maintenance OCS at inclusion was higher $(92.8 \%)$ than in the MENSA and MUSCA studies $(23-27 \%)[13,15]$. These findings are not unexpected, since patients in the nATU had a justified need to receive mepolizumab before it became commercially available. There also appears to be an over-representation of late-onset, eosinophilic asthma with nasal polyposis in the nATU population compared with the MUSCA trial (38.7\% of patients in the nATU versus $17-21 \%$ in MUSCA) [15]. Nonetheless, disease severity in this study was similar to that of a real-world study of patients receiving omalizumab [20] and other early access programmes, including the omalizumab and dupilumab ATUs in France [21, 22].

The prevention of exacerbations remains an important therapeutic target for patients with asthma [23]. In this study, we observed an $86.2 \%$ reduction from baseline in exacerbation rate after both 12 and 24 months of follow-up. In MENSA (MEpolizumab as adjunctive therapy iN patients with Severe Asthma) and 

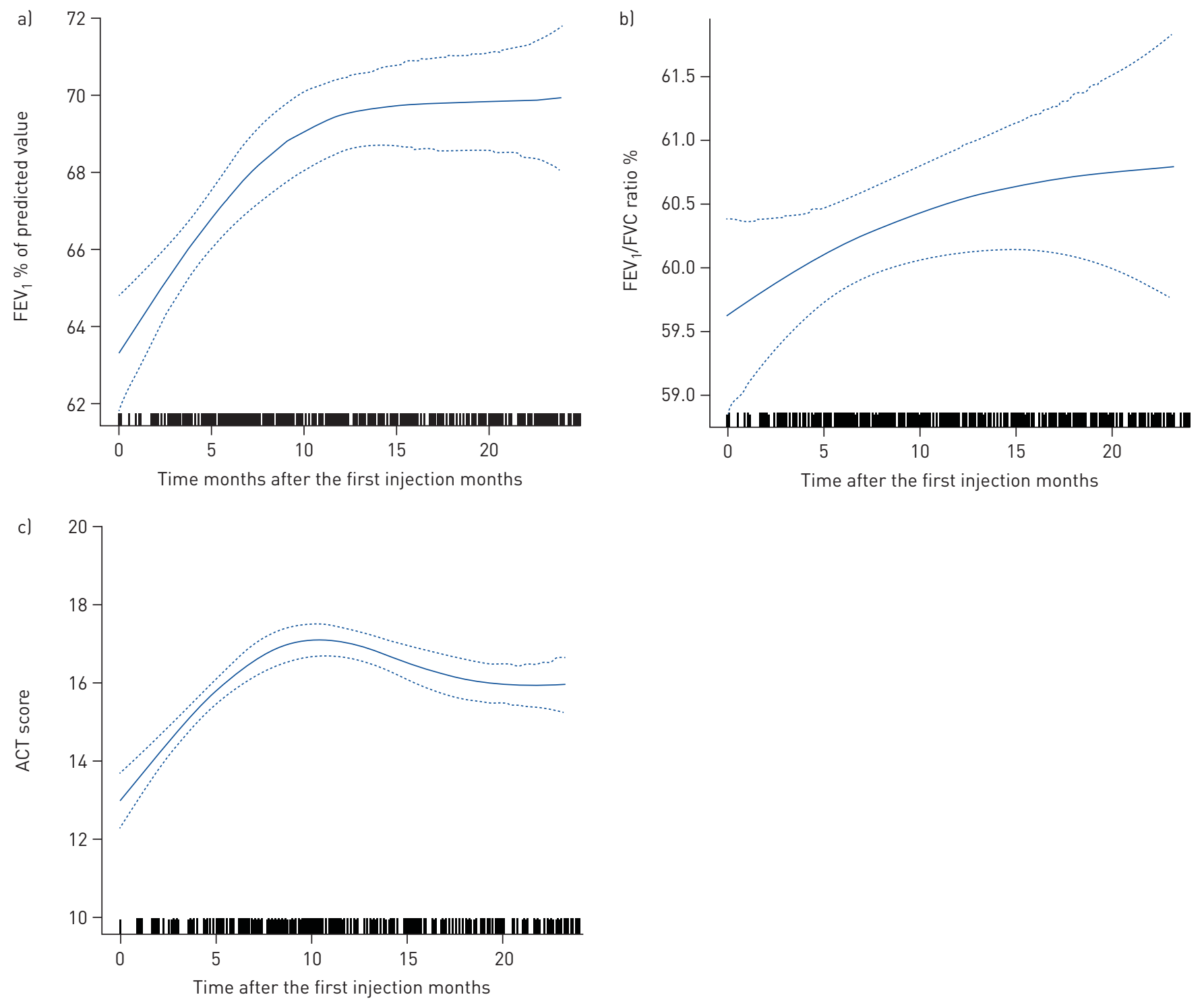

FIGURE 2 a) Evolution of percent-predicted pre-bronchodilator forced expiratory volume in $1 \mathrm{~s}\left(\mathrm{FEV}_{1}\right)$ b) $\mathrm{FEV}_{1} /$ forced vital capacity $(\mathrm{FVC})$ ratio and c) Asthma Control Test (ACT) score during the follow-up period. Continuous lines represent evolution of each score; dotted lines indicate the confidence interval. 
FIGURE 3 Evolution of eosinophil counts during the follow-up period. Continuous lines represent evolution of each score; dotted lines indicate the confidence interval.

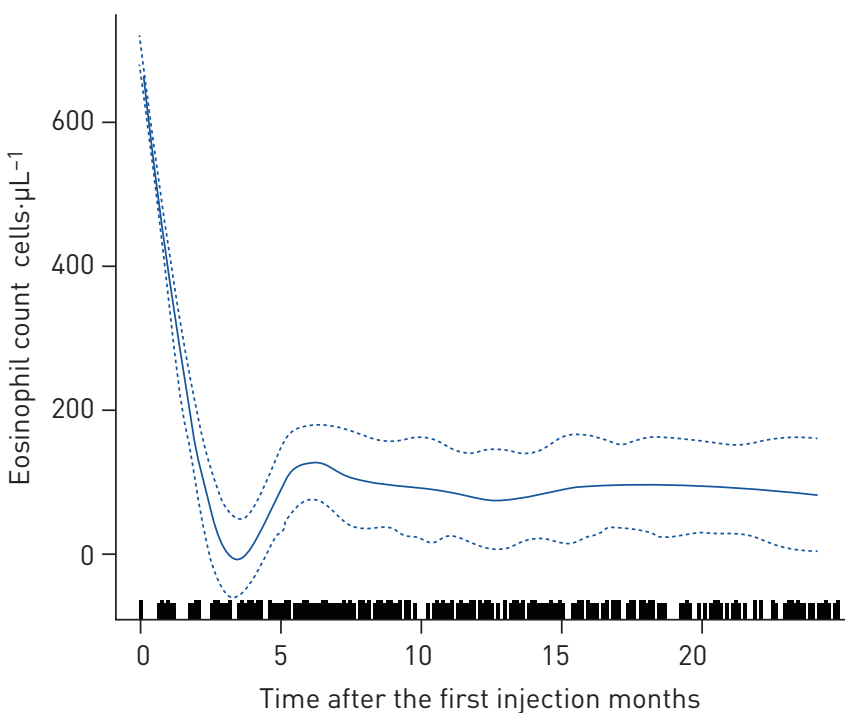

TABLE 3 Adverse events and serious adverse events considered possibly related to study drug, according to patient medical records

Event SOC/PT

Patients $\mathrm{n}$

\section{Total}

Adverse events possibly related to mepolizumab $\mathrm{n}$

General disorders and administration site conditions

Nervous system disorders

Respiratory, thoracic and mediastinal disorders

Gastrointestinal disorders

Musculoskeletal and connective tissue disorders

Skin and subcutaneous tissue disorders

Vascular disorders

Infections and infestations

Injury, poisoning and procedural complications ${ }^{\#}$

Renal and urinary disorders

Cardiac disorders

Ear and labyrinth disorders

Eye disorders

Immune system disorders

Investigations

Pregnancy, puerperium and perinatal conditions

Reproductive system and breast disorders

Serious adverse events possibly related to mepolizumab $\mathbf{n}$

Respiratory, thoracic and mediastinal disorders

Musculoskeletal and connective tissue disorders

General disorders and administration site conditions

Nervous system disorders

Infections and infestations

Hepatobiliary disorders

Most common drug-related adverse and serious adverse events possibly

related to mepolizumab ( $\mathrm{n} \geqslant 5 \%$ )

Drug ineffective

Headache

Asthmaף

Asthenia
Events

100

173

99

$62(39.0)$

$24(15.1)$

$21(13.2)$

14 (8.8)

$10(6.3)$

9 (5.7)

5 (3.1)

3 (1.9)

2 (1.3)

$2(1.3)$

$1(0.6)$

$1(0.6)$

$1(0.6)$

$1(0.6)$

$1(0.6)$

$1(0.6)$

$1(0.6)$

14

$4(28.6)$

$3(21.4)$

2 (14.3)

2 (14.3)

2 (14.3)

1 (7.1)

$31\left(17.9^{+}\right)$

$14\left(8.1^{+}\right)$

$13\left(7.5^{+}\right)$

$12\left(6.9^{+}\right)$

46

20

13

10

7

9

4

2

2

2

1

1

1

1

1

1

1

8

8

2

1

2

2

2

1
Data are presented as $\mathrm{n}$ or $\mathrm{n}(\%)$, unless otherwise stated. SOC: System Organ Class; PT: preferred term. \#: Excluding 103 events of inappropriate schedule of product administration for 61 patients; ๆ: included exercise induced asthma, asthmatic crisis, and aggravated condition; ${ }^{+}:$percentage of total drug-related adverse events and serious adverse events $(\mathrm{N}=173)$. 
TABLE 4 Adverse events of interest $(\mathrm{N}=15)$

Event SOC/PT

Events

$\begin{array}{lc}\text { Adverse events related to allergic and non-allergic reactions } & 2(13.3) \\ \text { Generalised rash } & 1(6.7) \\ \text { Rash } & 1(6.7) \\ \text { Local injection-site reactions } & 1(6.7) \\ \text { Injection-site erythema } & 1(6.7) \\ \text { Infections }^{\#} & 5(33.3) \\ \text { Herpes virus infection } & 1(6.7) \\ \text { Oral herpes } & 1(6.7) \\ \text { Pharyngitis } & 1(6.7) \\ \text { Pneumonia" } & 1(6.7) \\ \text { Purulent sputum" } & 1(6.7) \\ \text { Malignancies } & \S \\ \text { Vascular disorders } & 5(33.3) \\ \text { Hot flush } & 3(20.0) \\ \text { Capillary fragility } & 1(6.7) \\ \text { Hypertension } & 1(6.7) \\ \text { Cardiac disorders } & 1(6.7) \\ \text { Palpitations } & 1\end{array}$

Data are presented as $\mathrm{n}(\%)$. SOC: System Organ Class; PT: preferred term. " : Based on the Infections and Infestations SOC; ${ }^{\text {ๆ: }}$ events deemed serious by the treating investigator; ${ }^{+}$: based on the Neoplasms SOC; §: not reported.

is a greater proportion of patients than in our study, OCS doses are typically lowered more gradually in a real-world setting than in the down-titration protocols followed in RCTs. It is therefore likely that OCS tapering was conducted more slowly in our study than in SIRIUS, as supported by peak improvements in $\mathrm{FEV}_{1}$ and ACT score after 6 months of mepolizumab in the nATU. Moreover, we observed a relapse in OCS use/dose at 24 months of follow-up. However, this may be explained by differences in the number of patients between timepoints ( 18 months; $\mathrm{n}=91$ and 24 months; $\mathrm{n}=75$ ).

With regards to safety, we found that over the 24-month study period, headache and asthma were the most commonly reported adverse events and the occurrence of allergic, non-allergic and injection-site reactions was low. These results are in agreement with those from RCTs [14, 15], and indicate that mepolizumab is well tolerated in a setting that more closely resembles real life. During the nATU, 48 patients discontinued mepolizumab, 11 of whom reported a lack of drug efficacy associated with adverse events. The high discontinuation rate observed (32.9\%) may be explained by mepolizumab being a new product at the time of the study with no market approval, and thus no available stopping rules or guidelines. As such, physicians could stop treatment after a few months if no benefit was seen.

The main limitation of this study was the retrospective nature of the data collection and analysis. It should be noted that ACT score data were missing for approximately $40-60 \%$ of patients, although we did observe changes from baseline in ACT scores that exceeded the MCID in those patients with data available. The patients who discontinued mepolizumab in this study (owing to adverse events or lack of efficacy) were not included in the safety and efficacy results; since these measures depend on both the number of patients participating in the analysis and the duration of treatment, the data reported should be interpreted with caution. In addition, baseline ICS doses were not recorded in the medical data used for this study; these therefore could not be included in our assessments of baseline characteristics and evolution of disease among the nATU patient population. Results may also be subject to confounding factors, such as more stringent compliance, resulting from the regular contact with healthcare professionals that is required for biologic administration, or from patients having previously received another biologic therapy (e.g. omalizumab). Finally, patients in this study had particularly severe disease, based on the nATU criteria for early access to treatment, and were treated at University hospitals with expertise in managing severe asthma. As a result, our data may not be reflective of the overall severe asthma population, particularly those who receive care outside of this environment.

Nonetheless, these data from patients with severe eosinophilic asthma who received mepolizumab in the French early access programme confirm the effectiveness of mepolizumab in reducing exacerbation rates and OCS dependency as well as improving lung function in a setting which closely resembles real-life use. In addition, safety findings were consistent with those observed in clinical trials. Although additional 
studies are needed to fully assess the safety and effectiveness of mepolizumab in real-world, long-term, clinical practice, this analysis provides useful information for physicians who are considering treatment options for their patients with severe eosinophilic asthma.

Acknowledgements: The authors would like to thank the following participating investigators, who were involved in the collection of data for this study: PR Burgel, C Chenivesse, LJ Couderc, F De Blay, N Freymond, S Fry, PO Girodet, C Leroyer, A Magnan, S Marchand-Adam A Proust, C Raherison-Semjen and N Roche. Editorial support (in the form of writing assistance, including development of the initial draft based on author direction, assembling tables and figures, collating authors' comments, grammatical editing and referencing) was provided by Sarah Farrar, PhD, and Bianca Paris, PhD, at Fishawack Indicia Ltd, UK, and was funded by GSK.

Author contributions: $\mathrm{CT}, \mathrm{PC}, \mathrm{GD}, \mathrm{AD}, \mathrm{CP}, \mathrm{GG}, \mathrm{JC}, \mathrm{AB}$ and $\mathrm{MH}$ contributed to the acquisition of data during the analysis. $\mathrm{CT}, \mathrm{PC}, \mathrm{GD}, \mathrm{AD}, \mathrm{ChP}, \mathrm{GG}, \mathrm{AG}, \mathrm{CeP}, \mathrm{AB}$ and $\mathrm{MH}$ contributed to the conception and design of analysis; all authors contributed to the interpretation of the data, development of the manuscript and approval of the final draft. All authors had access to the study data. The decision to submit for publication was that of the authors alone; the sponsor did not place any restrictions on access to the data or on the statements made in the manuscript.

Conflict of interest: C. Taillé reports that the study and manuscript preparation support was funded by GlaxoSmithKline; grants and personal fees for consultancy and lectures from GlaxoSmithKline, AstraZeneca, Novartis, Roche, Sanofi, Chiesi and TEVA, outside the submitted work. P. Chanez reports that the study and manuscript preparation support was funded by GlaxoSmithKline; personal fees for advisory board work from Almirall, grants and personal fees for lectures from Alk-Abello, Boston Scientific and Centocor, grants and personal fees for consultancy, advisory board work and lectures from AstraZeneca, Boehringer Ingelheim, Chiesi, GSK, Novartis and Teva, personal fees for consultancy and advisory board work from Johnson \& Johnson and Sanofi, personal fees for consultancy from Merck Sharp \& Dohme, grants from Roche, outside the submitted work. G. Devouassoux reports that the study and manuscript preparation support was funded by GlaxoSmithKline; grants and personal fees for consultancy and meeting participation from Novartis Pharma, AstraZeneca, GlaxoSmithKline, ALK, TEVA, personal fees for consultancy and meeting participation from MundiPharma, grants and personal fees for consultancy from Boehringer Ingelheim, personal fees for consultancy from Vivisol, grants from Sanofi, Vitalair, AB Science, Amgen, Lilly and Roche, grants and personal fees for meeting participation from Chiesi and MSD, personal fees for meeting participation from AGIR a dom, Orkyn, Stallergene and Takeda, outside the submitted work. A. Didier reports that the study and manuscript preparation support was funded by GlaxoSmithKline; personal fees for consultancy and meeting participation from Novartis Pharma, AstraZeneca and GlaxoSmithKline, personal fees for consultancy from Chiesi, Boehringer Ingelheim, Mundi Pharma, TEVA, ALK and Menarini, outside the submitted work. C. Pison reports that the study and manuscript preparation support was funded by GlaxoSmithKline; grants, personal fees for lectures and non-financial support for meeting attendance from Novartis, AstraZeneca, GlaxoSmithKline, Chiesi, Boehringer Ingelheim and Sanofi, grants and personal fees for consultancy and lectures from Mundi Pharma and MSD, outside the submitted work. G. Garcia reports that the study and manuscript preparation support was funded by GlaxoSmithKline; personal fees for advisory board work from Novartis and Sanofi, personal fees for advisory board work and consultancy from AstraZeneca, personal fees for consultancy from GlaxoSmithKline, non-financial support for travel from Oxyvie, outside the submitted work. J. Charriot reports that the study and manuscript preparation support was funded by GlaxoSmithKline. S. Bouée reports that the study and manuscript preparation support was funded by GlaxoSmithKline; is an employee of CEMKA, and reports grants from GlaxoSmithKline, outside the submitted work. A. Gruber reports that the study and manuscript preparation support was funded by GlaxoSmithKline; and is an employee and shareholder of GlaxoSmithKline, outside the submitted work. C. Pribil reports that the study and manuscript preparation support was funded by GlaxoSmithKline; and is an employee and shareholder of GlaxoSmithKline, outside the submitted work. A. Bourdin reports that the study and manuscript preparation support was funded by GlaxoSmithKline; personal fees for clinical trial work from GlaxoSmithKline, AstraZeneca, Boehringer Ingelheim, Chiesi, Novartis and Sanofi, outside the submitted work. M. Humbert reports that the study and manuscript preparation support was funded by GlaxoSmithKline; personal fees for consultancy, speaking at conferences, and participation in clinical research projects from AstraZeneca, GlaxoSmithKline, Novartis, Roche, Sanofi and TEVA, outside the submitted work.

Support statement: This study (GSK ID: 207943; HO-17-18317) was funded by GSK. Editorial support was funded by GSK. Funding information for this article has been deposited with the Crossref Funder Registry.

\section{References}

1 Soriano JB, Abajobir AA, Abate KH, et al. Global, regional, and national deaths, prevalence, disability-adjusted life years, and years lived with disability for chronic obstructive pulmonary disease and asthma, 1990-2015: a systematic analysis for the Global Burden of Disease Study 2015. Lancet Respir Med 2017; 5: 691-706.

2 European Academy of Allergy and Clinical Immunology. Global Atlas of Asthma. Available from www.eaaci.org/ GlobalAtlas/Global_Atlas_of_Asthma.pdf Date last accessed: September 11, 2019; date last updated: June 22, 2013.

3 Hekking p-PW, Wener RR, Amelink M, et al. The prevalence of severe refractory asthma. J Allergy Clin Immunol 2015; 135: 896-902.

4 Chung KF, Wenzel SE, Brozek JL, et al. International ERS/ATS guidelines on definition, evaluation and treatment of severe asthma. Eur Respir J 2014; 43: 343-373.

5 Pavord ID, Beasley R, Agusti A, et al. After asthma: redefining airways diseases. Lancet 2018; 391: 350-400.

6 Kuruvilla ME, Lee FE-H, Lee GB. Understanding asthma phenotypes, endotypes, and mechanisms of disease. Clin Rev Allergy Immunol 2019; 56: 219-233.

7 Holguin F, Cardet JC, Chung KF, et al. Management of severe asthma: a European Respiratory Society/American Thoracic Society Guideline. Eur Respir J 2019; 55: 1900588.

8 Buhl R, Humbert M, Bjermer L, et al. Severe eosinophilic asthma: a roadmap to consensus. Eur Respir J 2017; 49: 1700634 . 
9 Menzella F, Lusuardi M, Galeone C, et al. Profile of anti-IL-5 mAb mepolizumab in the treatment of severe refractory asthma and hypereosinophilic diseases. J Asthma Allergy 2015; 8: 105-114.

10 European Medicines Agency. Assessment Report - Nucala. Available from www.ema.europa.eu/en/documents/ variation-report/nucala-h-c-3860-ii-0013-g-epar-assessment-report-variation_en.pdf Date last accessed: May 4, 2020; date last updated: November 18, 2019.

11 GlaxoSmithKline. Mepolizumab (NUCALA) US prescribing information. Available from https://gsksource.com/ pharma/content/dam/GlaxoSmithKline/US/en/Prescribing_Information/Nucala/pdf/NUCALA-PI-PIL.PDF Date last accessed: May 4, 2020; date last updated: September 30, 2019.

12 Global Initiative for Asthma. Global strategy for asthma management and prevention. Available from https:// ginasthma.org/wp-content/uploads/2019/06/GINA-2019-main-report-June-2019-wms.pdf Date last accessed: July 30, 2019; date last updated: April 12, 2019.

13 Ortega HG, Liu MC, Pavord ID, et al. Mepolizumab treatment in patients with severe eosinophilic asthma. $N$ Engl J Med 2014; 371: 1198-1207.

14 Bel EH, Wenzel SE, Thompson PJ, et al. Oral glucocorticoid-sparing effect of mepolizumab in eosinophilic asthma. N Engl J Med 2014; 371: 1189-1197.

15 Chupp GL, Bradford ES, Albers FC, et al. Efficacy of mepolizumab add-on therapy on health-related quality of life and markers of asthma control in severe eosinophilic asthma (MUSCA): a randomised, double-blind, placebocontrolled, parallel-group, multicentre, phase 3b trial. Lancet Respir Med 2017; 5: 390-400.

16 Pavord ID, Korn S, Howarth P, et al. Mepolizumab for severe eosinophilic asthma (DREAM): a multicentre, double-blind, placebo-controlled trial. Lancet 2012; 380: 651-659.

17 Pahus L, Alagha K, Sofalvi T, et al. External validity of randomized controlled trials in severe asthma. Am J Respir Crit Care Med 2015; 192: 259-261.

18 Launet Q, Brouard A, Doreau C. Drugs under temporary use authorisation: 50 years of French drug development. Rev Hist Pharm (Paris) 2004; 52: 47-54.

19 Patil S. Early access programs: benefits, challenges, and key considerations for successful implementation. Perspect Clin Res 2016; 7: 4-8.

20 Humbert M, Taillé C, Mala L, et al. Omalizumab effectiveness in patients with severe allergic asthma according to blood eosinophil count: the STELLAIR study. Eur Respir J 2018; 51: 1702523.

21 Molimard M, de Blay F, Didier A, et al. Effectiveness of omalizumab (Xolair) in the first patients treated in real-life practice in France. Respir Med 2008; 102: 71-76.

22 Caminati M, Cegolon L, Vianello A, et al. Mepolizumab for severe eosinophilic asthma: a real-world snapshot on clinical markers and timing of response. Expert Rev Respir Med 2019; 13: 1205-1212.

23 Bourdin A, Bjermer L, Brightling C, et al. ERS/EAACI statement on severe exacerbations in asthma in adults: facts, priorities and key research questions. Eur Respir J 2019; 54: 1900900.

24 Montero-Pérez O, Contreras-Rey MB, Sánchez-Gómez E. Effectiveness and safety of mepolizumab in severe refractory eosinophilic asthma: results in clinical practice. Drugs Context 2019; 8: 212584.

25 Strauss RA, Jawhari N. Mepolizumab in the treatment of severe eosinophilic asthma: Results from a physician in the field. Ann Allergy Asthma Immunol 2018; 121: 121-123.

26 Bagnasco D, Caminati M, Menzella F, et al. One year of mepolizumab. Efficacy and safety in real-life in Italy. Pulm Pharmacol Ther 2019; 58: 101836.

27 Pertzov B, Unterman A, Shtraichman O, et al. Efficacy and safety of mepolizumab in a real-world cohort of patients with severe eosinophilic asthma. J Asthma 2019; in press [https://doi.org/10.1080/02770903.2019. 1658208]. 